\title{
Calcium-dependent O-GlcNAc signaling drives liver autophagy in adaptation to starvation
}

\author{
Hai-Bin Ruan, ${ }^{1,2,7}$ Yina Ma, ${ }^{3,7}$ Sara Torres, ${ }^{1}$ Bichen Zhang, ${ }^{1,3}$ Colleen Feriod, ${ }^{3,4}$ Ryan $M$. Heck, ${ }^{2}$ \\ Kevin Qian, ${ }^{1}$ Minnie Fu, ${ }^{1}$ Xiuqi Li, ${ }^{1}$ Michael H. Nathanson, ${ }^{5}$ Anton M. Bennett, ${ }^{1,4}$ Yongzhan Nie, ${ }^{6}$ \\ Barbara E. Ehrlich, ${ }^{3,4}$ and Xiaoyong Yang ${ }^{1,3}$ \\ ${ }^{1}$ Program in Integrative Cell Signaling and Neurobiology of Metabolism, Department of Comparative Medicine, Yale University \\ School of Medicine, New Haven, Connecticut 06520, USA; ${ }^{2}$ Department of Integrative Biology and Physiology, University of \\ Minnesota, Minneapolis, Minnesota 55455, USA; ${ }^{3}$ Department of Cellular and Molecular Physiology, Yale University School of \\ Medicine, New Haven, Connecticut 06520, USA; ${ }^{4}$ Department of Pharmacology, Yale University School of Medicine, New Haven, \\ Connecticut 06520, USA; ${ }^{5}$ Section of Digestive Diseases, Department of Internal Medicine, Yale University School of Medicine, \\ New Haven, Connecticut 06520, USA; ${ }^{6}$ State Key Laboratory of Cancer Biology, Xijing Hospital of Digestive Diseases, Fourth \\ Military Medical University, Xi'an, Shaanxi 710032, China
}

Starvation induces liver autophagy, which is thought to provide nutrients for use by other organs and thereby maintain whole-body homeostasis. Here we demonstrate that $\mathrm{O}$-linked $\beta$ - $\mathrm{N}$-acetylglucosamine (O-GlcNAc) transferase (OGT) is required for glucagon-stimulated liver autophagy and metabolic adaptation to starvation. Genetic ablation of OGT in mouse livers reduces autophagic flux and the production of glucose and ketone bodies. Upon glucagon-induced calcium signaling, calcium/calmodulin-dependent kinase II (CaMKII) phosphorylates OGT, which in turn promotes O-GlcNAc modification and activation of Ulk proteins by potentiating AMPK-dependent phosphorylation. These findings uncover a signaling cascade by which starvation promotes autophagy through OGT phosphorylation and establish the importance of O-GlcNAc signaling in coupling liver autophagy to nutrient homeostasis.

[Keywords: O-GlcNAcylation; glucagon; CaMKII; Ulk; autophagy; glucose production]

Supplemental material is available for this article.

Received December 23, 2016; revised version accepted August 14, 2017.

Macroautophagy (referred to here as autophagy) is a cellular process in which cytoplasmic components are sequestered into double-membrane vesicles called autophagosomes and then degraded in lysosomes (Shintani and Klionsky 2004; Levine and Kroemer 2008; Rubinsztein et al. 2012). Various stress conditions, such as nutrient starvation and growth factor withdrawal, stimulate autophagy to produce energy and new building blocks (Rabinowitz and White 2010; Lin et al. 2012). In the liver, autophagy not only has a role in cell-autonomous quality control but also is critical for maintaining nutrient and energy balance during starvation. After depletion of glycogen stores, liver autophagy generates fatty acids and amino acids to be used for ATP production as well as gluconeogenesis and ketogenesis (Rabinowitz and White 2010). Defects in liver autophagy lead to increased triglyceride accumulation (Singh et al. 2009) and impaired amino acid release and glucose production (Ezaki et al. 2011). Liver autophagy is under the control of various hormones

\footnotetext{
${ }^{7}$ These authors contributed equally to this work.

Corresponding author: xiaoyong.yang@yale.edu

Article published online ahead of print. Article and publication date are online at http://www.genesdev.org/cgi/doi/10.1101/gad.305441.117.
}

and nutrients (Komatsu 2012; Codogno and Meijer 2013). Insulin and amino acids suppress autophagy through the mTOR pathway (Kim et al. 2011; Naito et al. 2013; Nazio et al. 2013). In contrast, glucagon induces autophagy, yet the physiological function and the underlying molecular mechanisms of glucagon-regulated autophagy are ill defined (Deter et al. 1967; Arstila and Trump 1968; Schworer and Mortimore 1979).

The molecular machinery of autophagy involves a series of protein complexes. The Ulk/Atg13/FIP200 complex is an essential regulator of autophagosome initiation. The class III PI3K complex, which contains Vps34, Beclin1, and Atg14L, promotes autophagosome nucleation. Subsequently, two ubiquitination-like systems form the Atg12/Atg5/Atg16L complex and phosphatidylethanolamine-conjugated LC3 (LC3-II) to mediate the expansion and closure of autophagosome membranes (Komatsu 2012). Post-translational modifications (PTMs)

C 2017 Ruan et al. This article is distributed exclusively by Cold Spring Harbor Laboratory Press for the first six months after the full-issue publication date (see http://genesdev.cshlp.org/site/misc/terms.xhtml). After six months, it is available under a Creative Commons License (Attribution-NonCommercial 4.0 International), as described at http:// creativecommons.org/licenses/by-nc/4.0/. 
on Ulk1 and Ulk2 serve as a nexus for the control of autophagic induction. When growth factors and nutrients are abundant, the active PI3K/Akt/mTOR pathway inhibits autophagy by directly phosphorylating Ulk1. Upon glucose deprivation, AMPK phosphorylates Ulk1 at different sites that activates Ulk1 to induce autophagy (Egan et al. 2011; Kim et al. 2011; Shang et al. 2011). In addition, Ulk1 acetylation and ubiquitination have also been shown to link growth factor deprivation to autophagy (Lin et al. 2012; Nazio et al. 2013). A complete understanding of Ulk PTMs will help elucidate how hormonal and nutritional signals converge on Ulk to initiate autophagy.

Thousands of cytoplasmic, nuclear, and mitochondrial proteins are modified by single O-linked $\beta$-N-acetylglucosamine (O-GlcNAc) moieties at serine or threonine residues, termed O-GlcNAcylation (Torres and Hart 1984; Yang and Qian 2017). Two enzymes mediate the addition and removal of O-GlcNAc: O-GlcNAc transferase (OGT) and O-GlcNAcase (OGA), respectively. This dynamic and reversible modification is a key regulator of diverse cellular processes, including signal transduction, transcription, translation, and proteasomal degradation (Ruan et al. 2012, 2013a; Li et al. 2013). Perturbations in protein O-GlcNAcylation are implicated in various human diseases such as obesity, diabetes mellitus, and cancer (Hart et al. 2011; Bond and Hanover 2013; Ruan et al. 2013b; Jozwiak et al. 2014). Because UDP-GlcNAc and protein O-GlcNAc levels in the cell fluctuate with the availability of glucose, free fatty acid (FFA), uridine, and the amino acid glutamine, O-GlcNAc is proposed to function as a nutrient sensor (Goldberg et al. 2006; Hanover et al. 2012). However, intriguingly enough, glucose deprivation and fasting signals can also promote protein O-GlcNAcylation despite relatively low levels of UDP-GlcNAc, indicating that O-GlcNAc signaling may function as a defense mechanism against falling energy status (Cheung and Hart 2008; Taylor et al. 2008; Kang et al. 2009).
O-GlcNAc signaling plays a critical role in multiple aspects of liver metabolism, including insulin sensitivity, glucose transport, glycogen synthesis, gluconeogenesis, and lipogenesis (Ruan et al. 2013b). Key components of insulin signaling, such as insulin receptors, insulin receptor substrates, PI3K, and Akt, can be O-GlcNAcylated (Whelan et al. 2010). The hexosamine pathway and OGlcNAcylation are known to negatively regulate hepatic insulin signaling (Veerababu et al. 2000; Yang et al. 2008). Hyperglycemia is also associated with O-GlcNAcylation of transcription factors and cofactors. For instance, O-GlcNAcylation of FOXO1, PGC-1 $\alpha$, and CRTC2 promotes the expression of gluconeogenic genes during fasting (Ruan et al. 2013b). The present study elucidates a novel glucagon $\rightarrow$ calcium/calmodulin-dependent kinase II (CaMKII) $\rightarrow$ OGT $\rightarrow$ Ulk1 pathway through which starvation induces liver autophagy to maintain systemic homeostasis. Mechanistically, we identify that CaMKIImediated phosphorylation of OGT induces Ulk OGlcNAcylation and activation, thereby mediating the effect of glucagon on liver autophagy.

\section{Results}

\section{Atg5-mediated autophagy is required for metabolic adaptation induced by glucagon}

To determine the role of autophagy in liver metabolism, we generated mice deficient for hepatic Atg5, which is conjugated with Atg12 and functions in a complex with Atg16L as an E3 ubiquitin ligase that is necessary for LC3-II formation and autophagosome elongation (Takamura et al. 2011). Adenovirus vectors expressing GFP and Cre were systemically injected into floxed homozygous $A \operatorname{tg} 5^{F / F}$ mice to generate control and liver-specific Atg5 knockout (Atg5-LKO) mice, respectively. Cre-mediated Atg5 knockout diminished the formation of the Atg12-Atg5 conjugate and LC3-II (Fig. 1A). Atg5-LKO
A
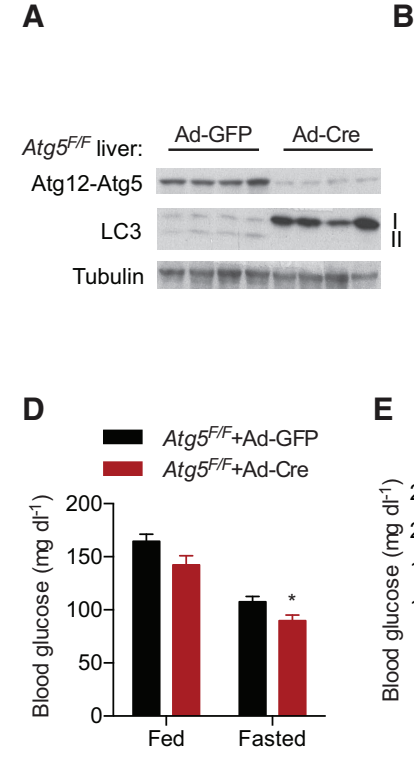

E
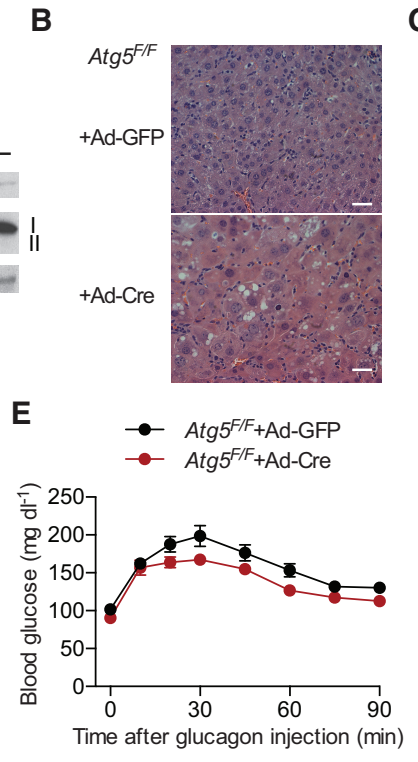
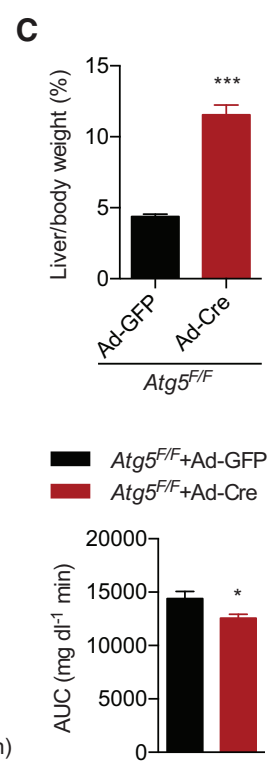

Figure 1. Atg5 regulates hepatic glucose production. (A) Western blotting of liver proteins showing the knockout of Atg5 and the defect in LC3 processing. Each lane represents an individual mouse sample. (B) Hematoxylin and eosin (H\&E) staining of liver sections from overnight fasted control and Atg5-LKO mice. Bar, $50 \mu \mathrm{m} .(C)$ Percentage of liver weight to body weight of overnight fasted control and Atg5LKO mice. $n=8$. $(D)$ Two weeks after adenoviral administration, levels of blood glucose in fed and overnight fasted mice were determined. $n=8$. $(E)$ One week after viral injection, $0.5 \mathrm{mg}$ of glucagon per kilogram of body weight was injected into overnight fasted mice, and glucose levels were measured for $90 \mathrm{~min}$. Area under curve (AUC) is shown at the right. $n=8$. Data are shown as mean \pm SEM. $\left({ }^{*}\right) P<0.05 ;\left(^{* * *}\right) P<$ 0.001 by Student's $t$-test. 
mice exhibited hepatocyte swelling and severe hepatomegaly (Fig. 1B,C), which are typical characteristics of an autophagic defect (Komatsu et al. 2005). Blood glucose levels were significantly lowered in overnight fasted Atg5LKO mice as compared with control mice (Fig. 1D). After an overnight fast, glycogen is depleted and glucagon promotes gluconeogenesis through the cAMP/PKA pathway and possibly the inositol trisphosphate receptor (InsP3R)/ CaMKII pathway (Jiang and Zhang 2003; Ozcan et al. 2012; Feriod et al. 2014). To test whether autophagy is required for the maintenance of fasting blood glucose, we performed a glucagon stimulation test in overnight fasted mice. Glucagon-induced elevation of blood glucose levels was significantly diminished in Atg5-LKO mice (Fig. 1E). In a pyruvate tolerance test, Atg5-LKO mice showed similar levels of blood glucose (Supplemental Fig. S1A), suggesting that the reduction in glucose during the glucagon stimulation test was not due to the dysfunction of gluconeogenic enzymes.

To test whether autophagy mediates the effect of glucagon in a cell-autonomous manner, primary hepatocytes were isolated and treated with glucagon. Glucagon increased LC3-II accumulation induced by bafilomycin A1 (BafA1; an inhibitor of autophagosome/lysosome fusion) significantly in control hepatocytes but to a much lower level in Atg5-deficient hepatocytes (Fig. 2A). In the absence of BafA1, glucagon reduced the levels of SQSTM1, a protein degraded through the autophagy pathway, in wild-type but not Atg5-deficient hepatocytes (Fig. 2A). Glucagon-induced glucose production was significantly blunted in Atg5-deficient hepatocytes (Fig. 2B). Autophagy breaks down protein and fat to produce amino acids and fatty acids, which are substrates for gluconeogenesis and ketogenesis during starvation. We found that glucagon increased the levels of L-amino acid (L-AA), FAA, and $\beta$-hydroxybutyrate $(\beta-\mathrm{HB}$; a major source of ketone bodies) in wild-type livers but not Atg5-deficient livers (Fig. 2C-E). These data demonstrate that Atg5-mediated autophagy in the liver is required for glucagon to induce the starvation response.
OGT mediates the role of glucagon-induced autophagy in liver metabolism

We next sought to dissect the molecular mechanism underlying glucagon-regulated liver autophagy. Global OGlcNAc levels were elevated in Atg5 knockout livers, suggesting an intrinsic association between protein $\mathrm{O}$ GlcNAcylation and autophagy (Supplemental Fig. S1BD). To directly determine the role of O-GlcNAc in the regulation of autophagy, we treated HEK293T cells overnight with thiamet-G (TMG), a specific inhibitor of OGA. We found that the elevation of O-GlcNAc levels by TMG increased the levels of LC3-II, which was further augmented by BafA1 (Fig. 3A). In mouse and human primary hepatocytes, TMG also increased LC3-II accumulation induced by BafA1 (Fig. 3B,C). Similarly, TMG treatment increased the number of LC3 puncta in HeLa cells stably expressing YFP-LC3 (Fig. 3D). Consistent with these results, OGT overexpression increased the levels of LC3-II in both 293T cells (Fig. 3E) and primary hepatocytes (Fig. 3F). BafA1 treatment further elevated the levels of LC3-II, suggesting that OGT promotes autophagic flux by activating early steps in autophagosome formation rather than by blocking autophagosome turnover at late stages (Klionsky et al. 2012).

To determine the physiological roles of OGT in vivo, the Ogt gene was knocked out specifically in livers (Ogt-LKO) by injecting Cre adenovirus into floxed $O g t^{F / Y}$ mice. Levels of LC3-II in 24-h fasted Ogt-LKO mice were significantly lower than those in control (Ad-GFP) mice (Fig. 4A). SQSTM1 displayed increased expression in Ogt-LKO mice (Fig. 4A). Electron microscopy further demonstrated that the amount of autophagic vacuoles was significantly less in the livers of Ogt-LKO mice than in those of control mice (Fig. 4B; Supplemental Fig. S2A). Alongside autophagic defects, levels of L-AA, FFA, glucose, and $\beta-\mathrm{HB}$ in the liver were all reduced in 24 - $\mathrm{h}$ fasted Ogt-LKO mice (Fig. 4C-F). Defects in liver autophagy were also observed in ad libitum fed and 48-h fasted Ogt-LKO mice (Supplemental Fig. S2B). Histological
A

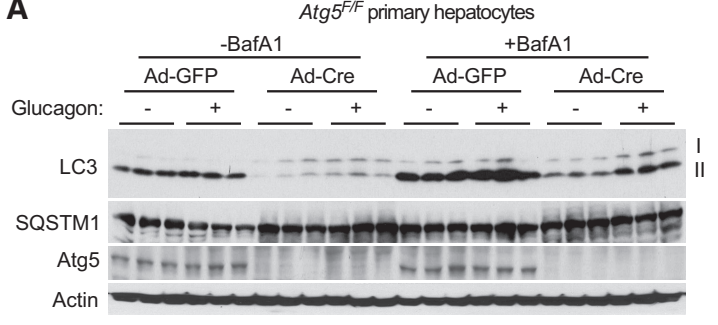

C

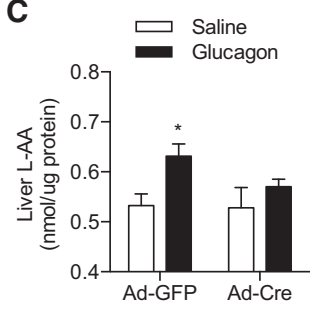

D

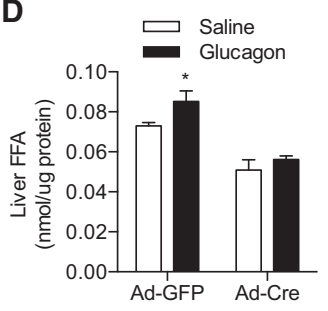

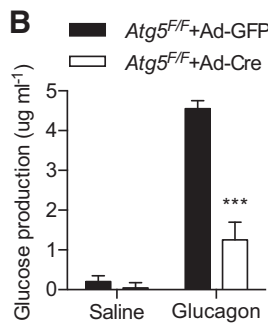

E

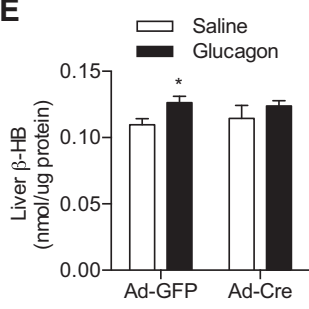

Figure 2. Autophagy mediates the effect of glucagon on liver metabolism. $(A, B)$ Primary hepatocytes from control and Atg5-LKO mice were treated with saline or $500 \mathrm{ng} / \mathrm{mL}$ glucagon for $4 \mathrm{~h}$. (A) Western blotting showing Atg5 and LC3-II levels in the absence and presence of BafA1. Each lane represents an individual mouse. $(B)$ Glucose release into glucose-free medium. $n=6 .(C-E)$ Two weeks after viral injection, overnight fasted mice were injected with saline or glucagon for 1 $\mathrm{h}$, and then liver tissues were collected for L-AA $(C)$, FFA $(D)$, and $\beta$-HB $(E)$ measurements. $n=4$. Data are shown as mean \pm SEM. $\left(^{*}\right) P<0.05$; $\left.{ }^{* * *}\right) P<0.001$ by Student's $t$-test. 
A
BafA1:

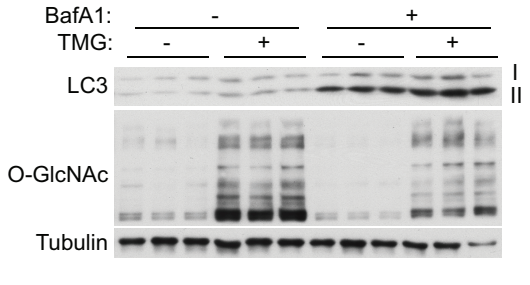

C

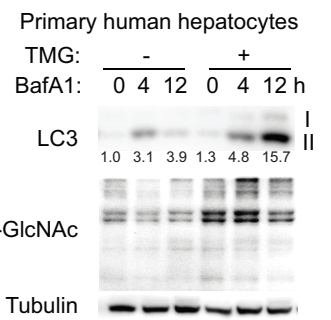

E

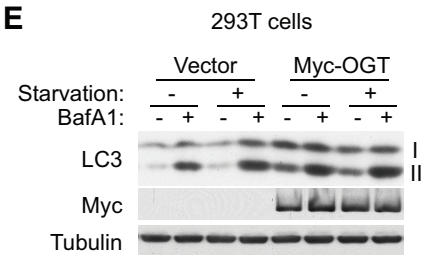

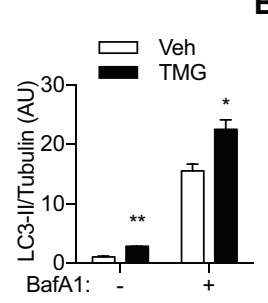

D
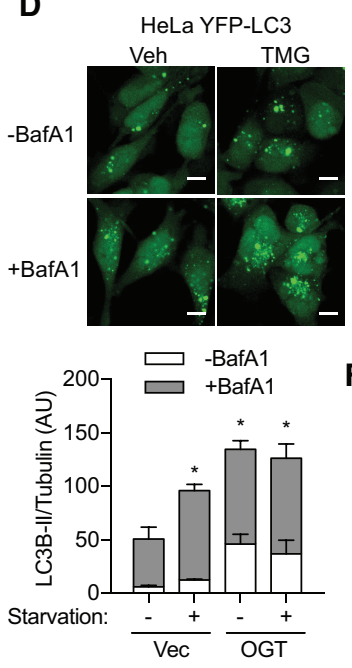

B

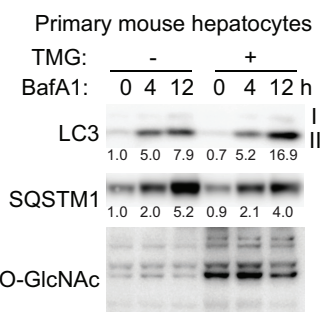

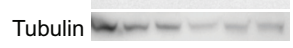

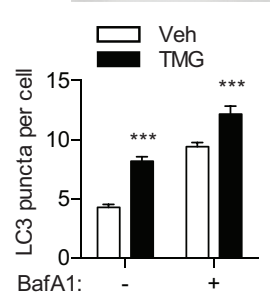

F

Primary mouse hepatocytes

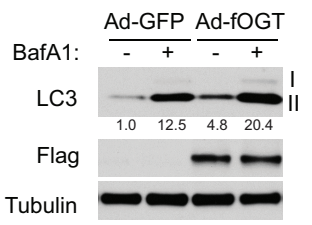

Figure 3. OGT promotes autophagy in cultured cells. (A) HEK293T cells were treated with TMG overnight and then starved in the presence or absence of BafA1, and levels of O-GlcNAc, LC3-II, and SQSTM1 were determined by Western blotting. LC3-II densitometry is shown at the right. $(B, C)$ Primary hepatocytes from mice $(B)$ and humans $(C)$ were treated with TMG overnight, and levels of O-GlcNAc and LC3-II were determined by Western blotting. Relative levels of LC3-II and SQSTM1 were quantified by densitometry of threeindependent experiments. $(D)$ Stable HeLa cells expressing YFP-LC3 were treated overnight with TMG followed by BafAl for $3 \mathrm{~h}$. LC3 puncta were observed by confocal microscopy, and the statistics are shown at the right. $n=123-144$. Bar, $50 \mu \mathrm{m}$. (E) HEK293T cells were transfected with empty vector or OGT and treated as indicated. LC3-II levels were determined by immunoblotting. Densitometry is shown at the right. $(F)$ Primary mouse hepatocytes were infected with adenoviruses expressing GFP or Flag-OGT and treated with BafAl as indicated. LC3-II levels were determined by immunoblotting and quantified by densitometry of three independent experiments. Data are shown as mean \pm SEM. $\left(^{*}\right) P<0.05$; $\left(^{* *}\right) P<$ 0.01 ; $\left(^{* * *}\right) P<0.001$ by Student's $t$-test $(A, D)$ or one-way ANOVA $(E)$.

analysis revealed hepatocyte swelling in knockout livers (Supplemental Fig. S2C). Accordingly, Ogt-LKO mice showed increased liver weight under the fed condition and lost less liver weight compared with controls after food deprivation (Supplemental Fig. S2D-G).

Glucagon-induced LC3-II accumulation in the livers of control mice but not in those of Ogt-LKO mice (Fig. 4G). Consistent with this observation, blood glucose levels in Ogt-LKO mice during a glucagon stimulation test were lower than those in control mice (Fig. 4H). TMG treatment of primary hepatocytes promoted glucose output into the medium, which was diminished in Atg5 knockout cells (Supplemental Fig. S2H), suggesting that the effect of O-GlcNAc on glucose metabolism is largely dependent on autophagy. Taken together, these data demonstrate that O-GlcNAc signaling acting downstream from glucagon maintains metabolic homeostasis through the up-regulation of autophagy.

\section{The InsP3R1-CaMKII pathway activates OGT and promotes liver autophagy}

To determine potential regulators linking glucagon to OGT-mediated autophagy, we predicted potential phosphorylation sites on human OGT protein using ScanSite (http://scansite3.mit.edu). One of the top hits is Ser20 by CaMKII (Supplemental Fig. S3A), and OGT phosphorylation at this site has been reported by mass spectrometry (Huttlin et al. 2010). To confirm the involvement of CaMKII, we performed an in vitro kinase activity assay using
CaMKII and wild-type OGT or Ser20-to-alanine (S20A) mutant OGT immunopurified from overexpressed HEK293T cells. CaMKII directly phosphorylated wildtype OGT but not S20A mutant OGT (Fig. 5A). S20A mutation did not significantly change global O-GlcNAc levels compared with the wild type; however, O-GlcNAcylation of specific proteins was impaired in S20A-expressing cells (Supplemental Fig. S3B). We generated an antibody specifically recognizing phospho-S20 OGT. Western blotting showed that nutrient starvation increased phosphorylation of wild-type OGT at S20 and that S20A mutation ablated this phosphorylation (Fig. 5B). Overexpression of wild-type but not S20A OGT increased the levels of LC3-II accumulation in 293T cells (Fig. 5C) and the numbers of LC3 puncta in HeLa cells (Fig. 5D). These data suggest that phosphorylation by CaMKII enables OGT to promote autophagy.

To directly determine whether CaMKII regulates autophagy, we overexpressed constitutively active mutant CaMKII (CA-CaMKII; T287D) in primary mouse hepatocytes via adenoviral vectors. The expression of CACaMKII increased the accumulation of LC3-II induced by the treatment of BafAl as compared with the untreated group (Fig. 5E), suggesting an increase in autophagic flux. It has been shown that CaMKII $\gamma$, the major isoform expressed in hepatocytes, is activated by glucagon and promotes hepatic glucose production (Ozcan et al. 2012). To test the role of CaMKII $\gamma$ in liver autophagy, we knocked out Camk2g by treating floxed Camk2 $g^{F / F}$ mice with hepatocyte-specific AAV8-TBG-Cre (Sun et al. 2012). We 
A

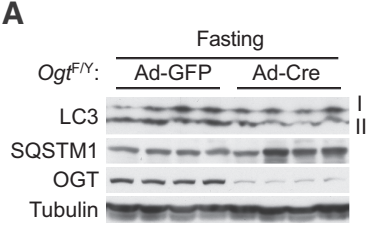

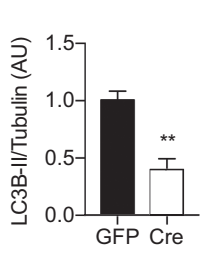

D

C

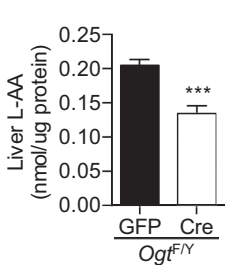

G

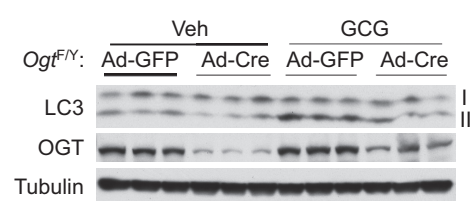

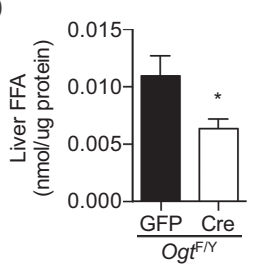

B

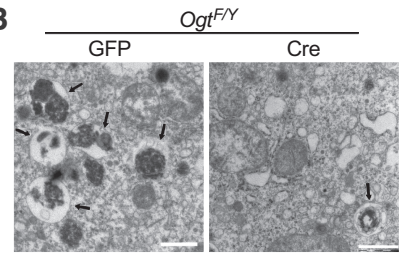

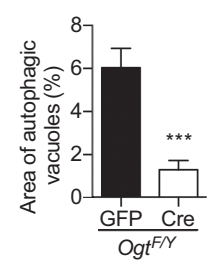

$\mathbf{F}$

E
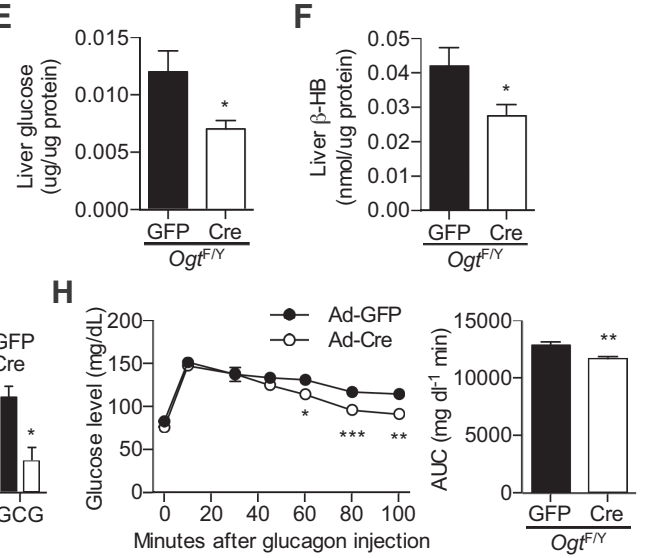

Figure 4. Hepatic OGT mediates metabolic adaptation to starvation. (A) Ogt ${ }^{F / Y}$ mice infected with adenoviruses encoding GFP (control) or Cre (Ogt-LKO) were fasted for $24 \mathrm{~h}$, and autophagy markers in liver lysates were determined by Western blotting. Each lane represents an individual mouse. Densitometry of LC3-II is shown at the right. (B) Representative electron micrographs of livers from 24-h fasted control and Ogt-LKO mice. Statistics of the area percentage of autophagic vacuoles is shown at the right. $n=21-36$. Bars, $1 \mu \mathrm{m}$. Arrows indicate autophagic vacuoles. $(C-F)$ Levels of free L-AA $(C)$, FFA $(D)$, glucose $(E)$, and $\beta-\mathrm{HB}(F)$ in the livers of overnight fasted mice. $n=7$. $(G)$ Hepatic LC3-II levels in control and Ogt-LKO mice treated with saline (Veh) or glucagon (GCG) for $1 \mathrm{~h}$. Each lane represents an individual mouse. Densitometry of LC3-II is shown at the right. $(H)$ Glucagon stimulation test in overnight fasted control and Ogt-LKO mice. AUC is shown at the right. $n=12-14$. Data are shown as mean \pm SEM. $\left({ }^{*}\right) P<0.05 ;\left({ }^{* *}\right) P<0.01 ;\left(^{* * *}\right) P<0.001$ by Student's $t$-test.

found that OGT activity (as measured by global OGlcNAc levels) and autophagy (as measured by LC3-II levels) were decreased in Camk2g-LKO mice (Fig. 5F). Accordingly, levels of L-AA, glucose, and $\beta$-HB in livers were all reduced in Camk2g-LKO mice (Fig. 5G-I). We also overexpressed HA-tagged CA-CaMKII in mouse livers (Pfleiderer et al. 2004). CA-CaMKII increased OGT phosphorylation and activity, as shown by pS20-OGT and O-GlcNAc blots, respectively (Fig. 5J). Increased LC3-II levels and decreased SQSTM1 levels indicate enhanced liver autophagy in CA-CaMKII mice (Fig. 5J). Blood glucose levels during a glucagon stimulation test were significantly higher in CA-CaMKII mice compared with GFP controls (Fig. 5K). The effect of CaMKII on glucose metabolism was dependent on the presence of OGT because CA-CaMKII failed to increase blood glucose when the Ogt gene was deleted in the liver (Fig. 5L).

The InsP3R type 1 (InsP3R1), an intracellular $\mathrm{Ca}^{2+}$ channel, mediates glucagon-induced $\mathrm{Ca}^{2+}$ release and CaMKII phosphorylation (Ozcan et al. 2012). We found that pretreatment of HEK293 cells with InsP3R antagonists xestospongin $\mathrm{C}(\mathrm{XesC})$ and 2-aminoethyl diphenylborinate (2-APB) inhibited starvation-induced CaMKII phosphorylation (Fig. 6A). In primary hepatocytes, knocking down Itpr1 decreased BafA1-induced accumulation of LC3-II, indicating that InsP3R1 promotes autophagic flux (Fig. 6B). To test the role of InsP3R1 in hepatic autophagy

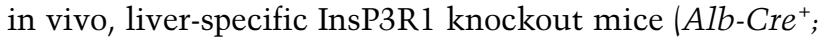

Itpr $1^{\mathrm{F} / \mathrm{F}}$ and Itpr1-LKO) were generated and shown to have decreased InsP3R1 expression only in livers (Feriod et al. 2017). Immunoblotting showed that hepatic levels of CaMKII phosphorylation, OGT phosphorylation at S20, global O-GlcNAc, and LC3-II were all down-regulated in Itpr1-LKO mice when fed (Supplemental Fig. S3C) or fasted (Fig. 6C) overnight. Moreover, blood glucose levels following glucagon treatment were reduced in Itpr1LKO mice compared with controls (Fig. 6D). Consistent with these results, hepatic levels of free L-AA and $\beta-\mathrm{HB}$ were down-regulated in Itpr1-LKO mice (Fig. 6E,F). Collectively, these data indicate that InsP3R1 is required for CaMKII activation and glucagon-induced autophagy in the liver.

\section{Ulk O-GlcNAcylation controls autophagy}

We next sought to determine the molecular targets of OGlcNAc signaling in the regulation of liver autophagy. The mammalian homologs of ATG1, Ulk1, and Ulk2 are key regulators in autophagy initiation. We found that both Ulk1 and Ulk2 are dynamically modified by OGlcNAc. Nutrient starvation dramatically increased OGlcNAc levels of both proteins (Fig. 7A; Supplemental Fig. S4A). OGT overexpression markedly increased Ulk1 O-GlcNAcylation (Fig. 7B). S20A mutant OGT retained the ability to bind to Ulk1 but failed to induce Ulk1 O-GlcNAcylation (Fig. 7B). In the liver, Ulk1 


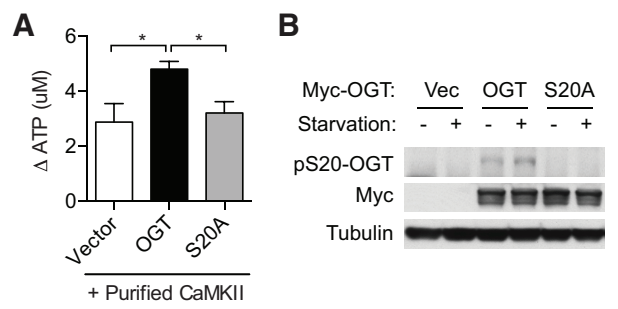

C
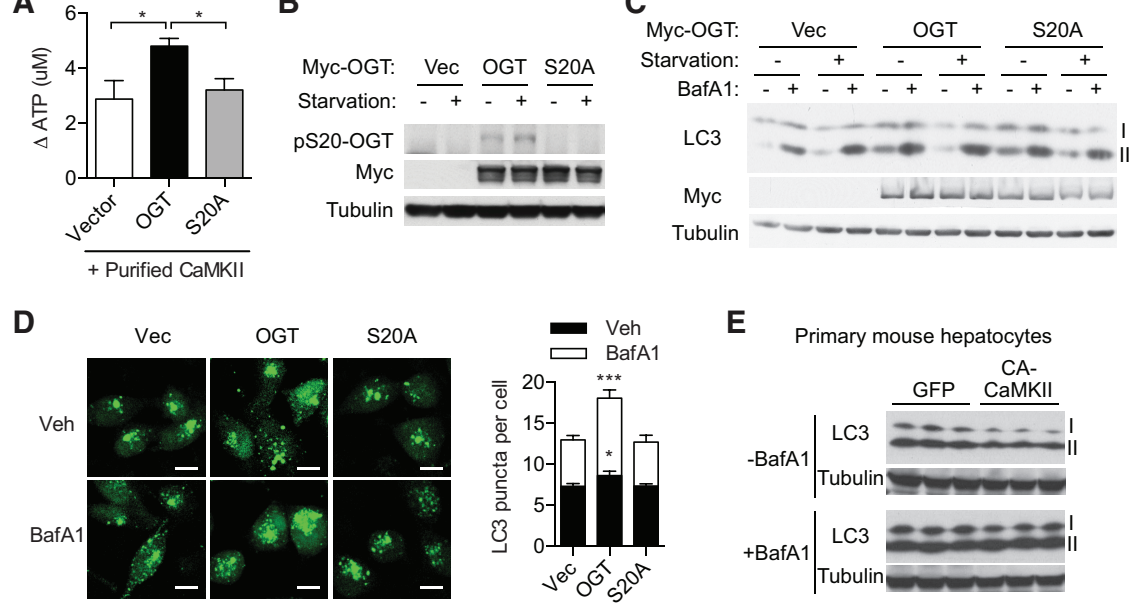

E
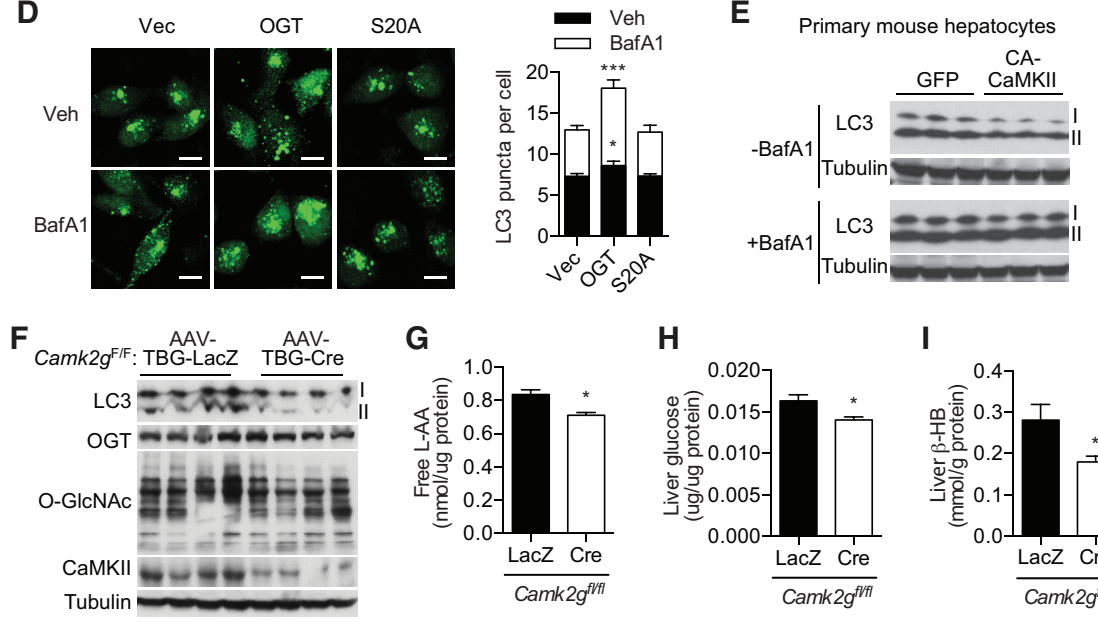

G

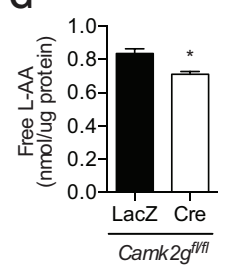

$\mathbf{H}$

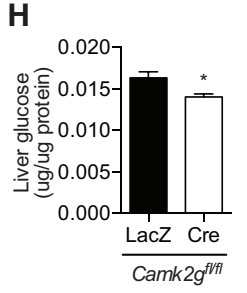

I

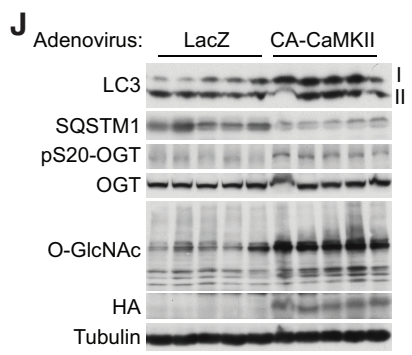

K
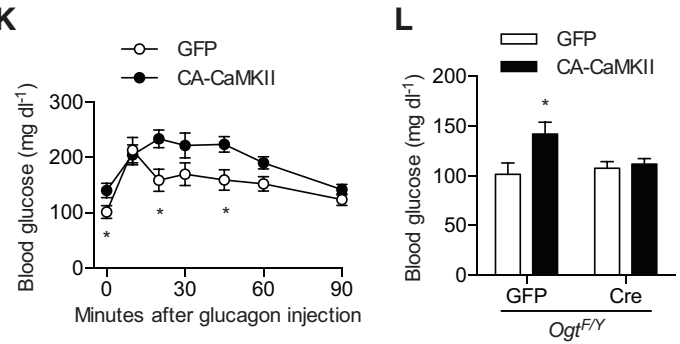

Figure 5. CaMKII controls OGT activity and liver autophagy. (A) CaMKII kinase activity on wild-type and S20A OGT. $n=4 .(B)$ HEK293T cells were transfected with wildtype or S20A mutant OGT and then starved in Earle's balanced salt solution (EBSS) for 3 h. Phospho-S20-specific antibody was used for immunoblotting. (C) Immunoblotting of LC3 of 293T cells transfected with wild-type or S20A mutant OGT followed by treatments as indicated. $(D)$ Stable HeLa cells expressing YFP-LC3 were transfected with OGT constructs, and LC3 puncta were visualized. Statistics are shown at the right. $n=66-104$. Bar, 10 $\mu \mathrm{m}$. (E) LC3-II levels in primary hepatocytes expressing GFP or constitutively active mutant CaMKII (CA-CaMKII) in the absence or presence of BafAl. (F-I) Diet-induced obese Camk2 $g^{F / F}$ mice were treated with hepatocyte-specific AAV-TBG-LacZ or AAV-TBG-Cre and fasted for $5 \mathrm{~h}$. $(F) \mathrm{Im}$ munoblotting of liver lysates. Levels of free L-AA $(G)$, glucose $(H)$, and $\beta$-HB $(I)$ are shown. $n=4$. (J) Immunoblotting of liver lysates from overnight fasted mice treated with Ad-LacZ and Ad-CA-CaMKII. (K) Glucagon stimulation test of overnight fasted mice. $n=5$. $(L)$ Ad-CA-CaMKII and Ad-Cre were coinjected into $\mathrm{Ogt}^{F / Y}$ mice to generate mice overexpressing hepatic CA-CaMKII on an Ogt-LKO background. Blood glucose levels in overnight fasted mice are shown. $n=5$. Each lane represents an individual mouse sample in $E, F$, and $J$. Data are shown as mean \pm SEM. $\left({ }^{*}\right) P<0.05$; $\left(^{* * *}\right)$ $P<0.001$ by one-way ANOVA $(A, D)$ and Student's $t$-test $(G-I, K, L)$.
O-GlcNAcylation was decreased in Ogt-LKO mice as compared with the wild type (Fig. 7C). Glucagon treatment for $1 \mathrm{~h}$ increased Ulk1 O-GlcNAcylation, which was largely attenuated in Ogt-LKO mice (Fig. 7C). These data support the notion that glucagon signaling modulates OGT activity to control Ulk1 O-GlcNAcylation.

Two O-GlcNAc sites on Ulk2 have been identified previously by mass spectrometric studies (Alfaro et al. 2012; Trinidad et al. 2012). These sites are conserved in human and mouse Ulk1 and Ulk2 proteins (Supplemental Fig. S4B), implying the importance of O-GlcNAcylation on Ulk proteins. These O-GlcNAcylation sites on Ulk1 and Ulk2 were mutated individually or simultaneously, and we observed decreased O-GlcNAc levels in all of these mutant proteins (Supplemental Fig. S4C). Beclin-1 is a recently identified substrate for Ulk kinases (Russell et al. 2013). When coexpressed with wild-type Ulk1 or Ulk2 in 293T cells, Beclin-1 was robustly phosphorylated at Ser15; in contrast, mutant Ulk proteins showed a diminished ability to phosphorylate Beclin-1 at this site (Fig. 7D; Supplemental Fig. S4D). In vitro kinase activity assays of Ulk1 and Ulk2 using purified Beclin-1 as the substrate also demonstrated that O-GlcNAc site-mutated proteins had lower kinase activity compared with wild-type Ulk1 and Ulk2 (Fig. 7E; Supplemental Fig. S4E).

O-GlcNAcylation has an extensive cross-talk with phosphorylation (Hart et al. 2011). Ulk1 is a highly phosphorylated protein, and emerging evidence demonstrates that AMPK positively regulates and $\mathrm{mTOR}$ negatively regulates Ulk1 activity by direct phosphorylation (Alers et al. 2012). We found that O-GlcNAcylation-deficient Ulk1 showed decreased phosphorylation on two AMPK phosphorylation sites (Ser555 and Ser638), but there were no changes in the phosphorylation on Ser317 by AMPK or on Ser757 by mTOR (Fig. 7F). Mutations of O-GlcNAc sites (particularly T635 and T635/754) reduced Ulk 1 interaction with AMPK (Fig. 7G), suggesting that Ulk1 OGlcNAcylation facilitates AMPK recruitment. Moreover, OGT knockdown abolished the accumulation of LC3-II induced by the AMPK activator AICAR (Fig. 7H), indicating that OGT is required for AMPK to promote autophagy.

To verify the functional importance of Ulk1 O-GlcNAcylation in autophagy, wild-type or T635/754A mutant Ulk1 was expressed in ULK-deficient HeLa cells stably expressing YFP-LC3. Compared with the wild type, expression of mutant Ulk1 decreased LC3 puncta formation in 
A

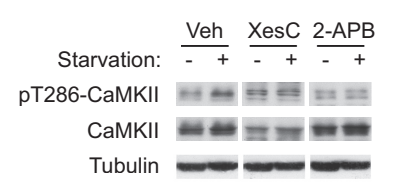

D

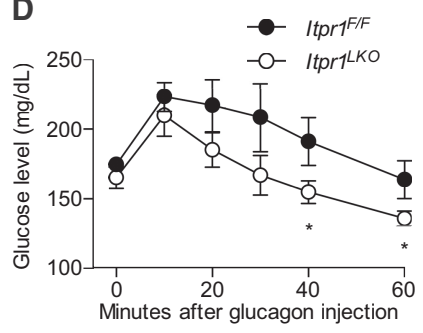

B
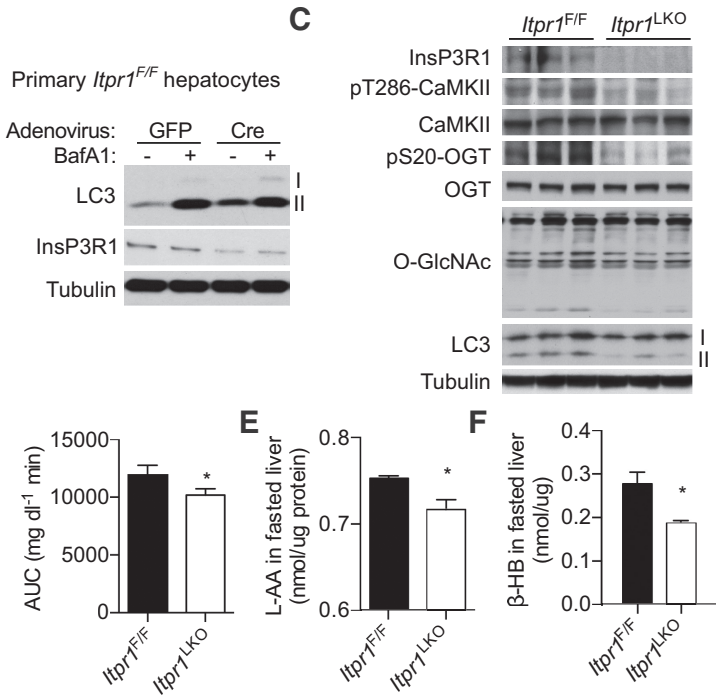

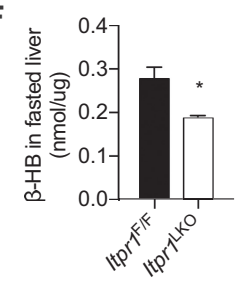

Figure 6. InsP3R1 regulates liver autophagy. (A) HEK293T cells were starved in EBSS medium in the absence or presence of the InsP3R antagonist XesC or 2-APB for $3 \mathrm{~h}$. Phospho-T286-CaMKII was determined by immunoblotting. (B) Primary hepatocytes from Itpr $1^{F / F}$ mice were infected with Ad-GFP or Ad-CA-CaMKII, and then LC3-II levels were determined by Western blotting. (C) Immunoblotting of liver lysates from overnight fasted control and Itpr1-LKO mice. Each lane represents an individual mouse. $(D)$ Glucagon stimulation tests of 6-h fasted control and Itpr1-LKO mice. AUC is shown at the right. $n=8$. $(E$, $F)$ Hepatic L-AA levels $(E)$ and serum $\beta$-HB levels $(F)$ of overnight fasted control and Itpr1-LKO mice. $n=8$. Data are shown as mean \pm SEM. $\left({ }^{*}\right) P<0.05$ by Student's $t$-test. the absence and presence of BafAl (Fig. 7I; Supplemental Fig. S4F). Taken together, these data demonstrate that Ulk1 O-GlcNAcylation promotes autophagy by facilitating AMPK-mediated Ulk1 phosphorylation.

\section{Discussion}

Autophagy is proposed to provide energy and nutrients under various stress conditions. Here we defined a vital role of liver autophagy in metabolic adaptation to starvation. We demonstrated that during starvation, glucagon stimulates liver autophagy to provide substrates for gluconeogenesis and ketogenesis to maintain systemic glucose homeostasis. We also established the glucagon-InsP3R1CaMKII pathway as a novel regulator of OGT activity, which targets Ulk proteins at the post-translational level to fine-tune liver autophagy.

Three groups recently showed that O-GlcNAc cycling enzymes are involved in autophagy in Caenorhabditis elegans and Drosophila, yet the physiological relevance is largely unknown (Wang et al. 2012; Guo et al. 2014; Park et al. 2015). Here we demonstrate for the first time that in mammalian cells and mouse livers, O-GlcNAc is required for autophagy initiation and glucose homeostasis during starvation. Guo et al. (2014) suggested that OGT prevents the fusion of autophagosomes with lysosomes, while we demonstrate that OGT also promotes the initiation of autophagy by O-GlcNAcylating and activating Ulk proteins. It is conceivable that by sensing different upstream signals and acting on distinct downstream targets, O-GlcNAc signaling has divergent effects on autophagic flux, arguing that optimal levels of O-GlcNAc are critical for autophagy regulation, cellular metabolism, and systemic homeostasis.

Under fasting conditions, liver autophagy can be induced by inactivating mTOR signaling. Here we demonstrate that O-GlcNAcylation promotes Ulk phosphorylation by AMPK, a known regulator of autophagy that functions cooperatively with mTOR (Egan et al. 2011;
Kim et al. 2011; Shang et al. 2011). We propose that the glucagon-CaMKII-OGT-Ulk pathway acts in parallel with the established insulin/amino acid-mTOR-Ulk pathway to modulate liver autophagy during starvation. Studying the interplay between the O-GlcNAc and mTOR signaling pathways in regulating autophagy will be important for future research. It is well established that AMPK can be directly phosphorylated and activated by $\mathrm{Ca}\left({ }^{2+}\right) /$ CAMK kinase (CaMKK) in response to $\mathrm{Ca}^{2+}$ flux (Woods et al. 2005). Future studies are required to determine the role of AMPK in glucagon-induced liver autophagy. Recent studies demonstrated that OGT and AMPK reciprocally modify and regulate each other (Bullen et al. 2014; Xu et al. 2014). Therefore, these two essential nutrient-sensitive pathways may cooperatively regulate autophagy at multiple levels.

Simply starving the cells in Earle's balanced salt solution (EBSS) medium will induce CaMKII phosphorylation (Fig. 6A), OGT phosphorylation (Fig. 5B), and Ulk O-GlcNAcylation (Fig. 7A), suggesting that there is a glucagon-independent regulation of the CaMKII-OGT-Ulk pathway. It has been shown previously that serum/amino acid starvation of cells both stimulates the InsP3R to release $\mathrm{ER} \mathrm{Ca}^{2+}$ and activates Mucolipin1 to promote lysosomal $\mathrm{Ca}^{2+}$ release (Decuypere et al. 2011; Medina et al. 2015). These mechanisms can potentially activate the CaMKII-OGTUlk pathway in a glucagon-independent manner.

Emerging data suggest a close relationship between CaMKII and O-GlcNAc. Erickson et al. (2013) showed that in diabetic hyperglycemia, O-GlcNAcylation of CaMKII activates CaMKII and contributes to heart failure. On the other hand, our work demonstrates that CaMKII phosphorylates OGT and facilitates Ulk O-GlcNAcylation in response to glucagon. These two studies are distinct and complementary, suggesting a potential feedforward mechanism between OGT and CaMKII to amplify $\mathrm{Ca}^{2+}$ signals in various physiological and pathophysiological settings.

Progressive type 2 diabetes is associated with dysregulated glucagon secretion (D'Alessio 2011), hyper-O- 


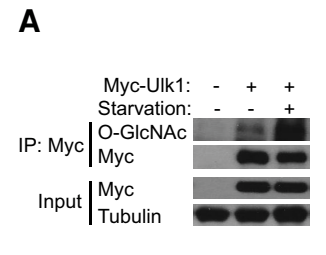

B
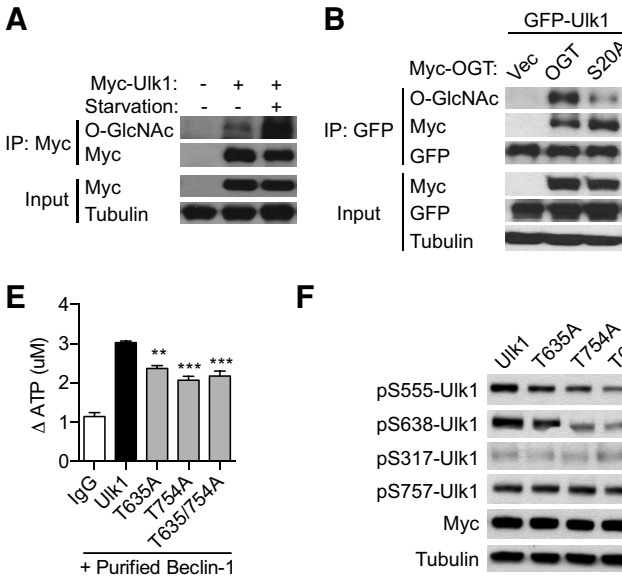

$\mathbf{F}$

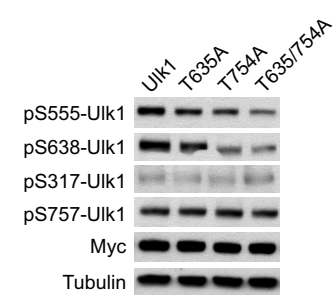

C

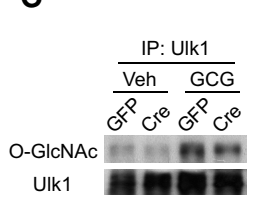

D

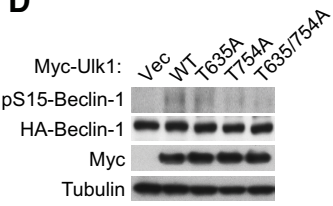

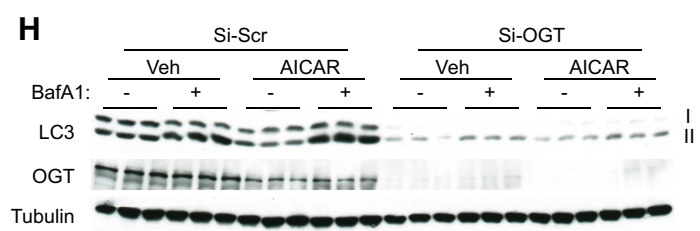

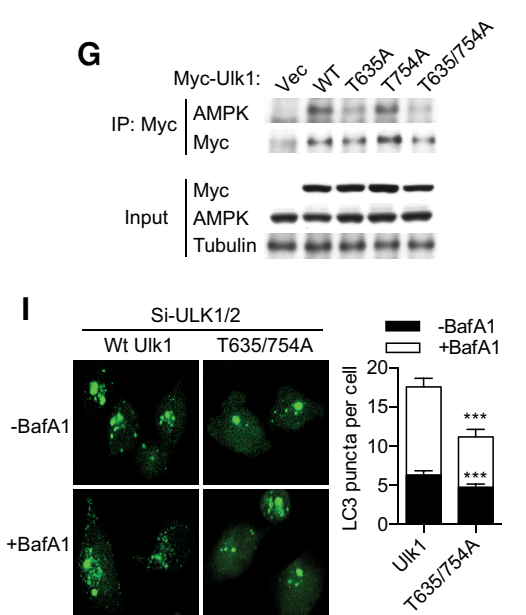

Figure 7. O-GlcNAcylation modulates Ulk phosphorylation and activity. (A) O-GlcNAcylation of Ulk1 in HEK293T cells treated with or without EBSS starvation for $3 \mathrm{~h}$. (B) Ulk1 O-GlcNAcylation in 293T cells cotransfected with wild-type or S20A mutant OGT. (C) Ulk1 OGlcNAcylation in livers from control or Ogt-LKO mice treated with saline or glucagon for $1 \mathrm{~h}$. $(D)$ Phosphorylation levels of Beclin-1 at S15 when cotransfected with wild-type or O-GlcNAc site-mutated Ulk1 in $293 \mathrm{~T}$ cells. (E) In vitro Ulk1 activity assay using purified Beclin-1 as the substrate. $n=3$. $(F)$ Site-specific phosphorylation of wild-type and O-GlcNAc site-mutated Ulk1 in $293 \mathrm{~T}$ cells. $(G)$ Interaction between overexpressed Ulk1 proteins and endogenous AMPK as shown by immunoprecipitation in 293T cells. $(H)$ 293T cells transfected with siRNAs against scrambled sequence (Si-Scr) or human OGT (Si-OGT) were treated with or without AICAR in the presence or absence of BafAl for $4 \mathrm{~h}$. LC3-II levels were determined by immunoblotting. (I) Wild-type or T635/754A mutant mouse Ulk1 proteins were reconstituted into YFP-LC3 stable HeLa cells in which endogenous ULK1 and ULK2 were knocked down. Cells were treated with vehicle or BafA1. LC3 puncta were counted and are plotted at the right. $n=18-35$. Data are shown as mean \pm SEM. $\left(^{* *}\right) P<0.01 ;\left({ }^{* * *}\right) P<0.001$ by ANOVA $(E)$ or Student's $t$-test $(I)$.

GlcNAcylation (Ruan et al. 2013b), and excessive glucose production and ketoacidosis. Our study provides an integrated understanding of how O-GlcNAc signaling links glucagon-induced autophagy to glucose and ketone metabolism. This lays the groundwork for future therapeutics against diabetes and related disorders in humans.

\section{Materials and methods}

Mice

$\operatorname{Atg} 5^{F / F}$ mice were generated previously and were kindly provided by Akiko Iwasaki and Gerald Shulman at Yale University (Hara et al. 2006). $O g t^{f l o x}$ mice on a C57BL/6 background were kindly provided by Dr. Steven Jones at University of Louisville (Shafi et al. 2000). Camk2 $g^{F / F}$ mice on a C57BL/6 background, generated as described previously, were kindly provided by Dr. Eric Olson at University of Texas Southwestern Medical Center (Backs et al. 2010). To generate liver-specific Atg5, Ogt, and Camk2g knockout mice, $1 \times 10^{9}$ plaque forming units (pfu) of adenovirus or AAV expressing Cre was delivered into $\operatorname{Atg} 5^{F / F}$, $O g t^{F / Y}$, and Camk2 $g^{F / F}$ mice by systemic tail vein injection. Adenovirus and AAV expressing GFP or LacZ were used as controls. Itpr $1^{F / F}$ mice were generated by the Andrew Marks laboratory at Columbia University and crossed with the Alb-Cre strain to generate Itpr1-LKO. All animals were kept on a 12-h:12-h light:dark cycle. Mice were free to access water and either fed on a standard chow diet or $60 \%$ high-fat diet (Research Diets). All procedures have been approved by the Institutional Animal Care and Use Committee of Yale University.

\section{Metabolic assays}

For pyruvate tolerance tests and glucagon stimulation tests, 16-h fasted mice were injected intraperitoneally with $1.5 \mathrm{~g}$ of sodium pyruvate (Sigma) per kilogram of body weight or $0.5 \mathrm{mg}$ of glucagon (Eli Lilly) per kilogram of body weight. Blood glucose from tail vein blood collected at the designated times was measured using a Nova Max glucometer. Levels of free L-AA (Sigma, catalog no. MAK002), FFA (Sigma, catalog no. MAK044), and $\beta$-HB (Cayman Chemical, catalog no. 700190) in serum and livers were determined according to the manufacturers' manuals.

\section{Histology}

Mouse livers were dissected and fixed in $4 \%$ paraformaldehyde (PFA) and sectioned. Hematoxylin and eosin (H\&E) staining was performed by the Histology Laboratory in the Section of Comparative Medicine. For electron microscopy, mice were perfused with PBS followed by $4 \%$ PFA. Liver tissues were cut into $<1 \times$ $1 \times 1-\mathrm{mm}^{3}$ cubes for post-fixation overnight in $2.5 \%$ gluteraldehyde and $2 \%$ PFA in $0.1 \mathrm{M}$ sodium cacodylate buffer. Embedding, sectioning, and observation were carried out at the Electron Microscopy Core at Yale School of Medicine. 
Plasmids and viruses

pcDNA4-Beclin-1-HA (no. 24399) and pcDNA6.2-Myc-Ulk1 (no. 27629) were purchased from Addgene. Myc/His tag at the C-terminal of mouse Ulk2 was cloned into the pcDNA3.1 vector. pCMV-Myc-human OGT was kindly provided by Dr. Xiaochun $\mathrm{Yu}$ at University of Michigan. pCR2/CMV-Myc-CaMKII $\gamma$ was kindly provided by Dr. Harold Singer at Albany Medical College. Point mutations of plasmids were obtained using the site-directed mutagenesis XL II kit from Agilent. Dr. Harold Singer also provided CaMKII adenovirus. Adenoviruses were amplified in HEK293 cells and purified using a kit from Virapur.

\section{Cell culture}

HEK293T cells were cultured in DMEM (Invitrogen) with 10\% fetal bovine serum (FBS; Gibco). Transfection of plasmids was performed using FuGENE HD (Promega) according to the manufacturer's manual. siRNAs were transfected using Lipofectamine 2000 (Invitrogen) when plating the cells. HeLa cells stably expressing YFP-LC3 were kindly provided by Dr. Thomas Melia Jr. at Yale University and cultured in DMEM with 10\% FBS. For starvation, cells were washed once with EBSS (Sigma) and incubated in EBSS for $3 \mathrm{~h}$. Ten micromolar TMG, $1 \mu \mathrm{M}$ BafAl (Cayman Chemical), $0.5 \mu \mathrm{M}$ XesC (CalBioChem), and $10 \mu \mathrm{M} 2$-APB (Sigma,) were treated as indicated. All cells were routinely tested to be mycoplasma free.

\section{Primary hepatocytes}

Primary hepatocytes were isolated by the Yale Liver Center Core Facility and plated in DMEM (5.5 mM glucose) with 10\% FBS on collagen I-coated plates (Corning). Hepatocytes were treated with glucose-free or amino acid-free DMEM (no phenol red) for 4 h. Glucose concentration in the medium was measured using a glucose oxidation kit (Sigma). The readings were then normalized to the total protein content.

\section{Antibodies, immunoprecipitation, and Western blotting}

Anti-OGT (ab96718), anti-O-GlcNAc (RL2, ab2739), and antiGFP (ab290) antibodies were from Abcam. Anti-Atg5 (no. 2630), anti-LC3B (no. 3868), anti-SQSTM1 (no. 5114), anti-CaMKII (no. 3362), anti-phospho-CaMKII (T286; no. 3361), anti-AMPK (no. 2532), anti-Ulk1 (no. 8054), anti-phospho-Ulk1 (S317; no. 12753), anti-phospho-Ulk1 (S555; no. 5869), anti-phospho-Ulk1 (S638; no. 12097), and anti-phospho-Ulk1 (S757; no. 6888) were from Cell Signaling Technology. Anti-Myc (sc-40) was from Santa Cruz Biotechnology. Anti-phospho-Beclin1 (S15) was from Abbiotec. Anti- $\alpha$-Tubulin (T5168), anti- $\beta$-Actin (A5441), antiFlag M2 (F3165), and anti-HA (H3663) were from Sigma-Aldrich. Mouse OGT-S20 phospho-specific antibody was generated in rabbits using the peptide antigen eptkrmlS(p)fqglael (BiologicsCorp). The antibody was purified through affinity column of the phospho-peptide and eliminated by native peptide eptkrmlsfqglael. ELISA demonstrated that the antibody specifically recognized the phosphorylated peptide but not the unphosphorylated peptide. Tissues were lysed in buffer containing $1 \%$ nonidet P-40, $50 \mathrm{mM}$ Tris. $\mathrm{HCl}$ (pH 8.0), $0.1 \mathrm{mM}$ EDTA, $150 \mathrm{mM} \mathrm{NaCl}$, proteinase inhibitors, and protein phosphatase inhibitors. For immunoprecipitation, whole-cell lysates were mixed with various antibodies as specified in the text and precipitated by protein A/G agarose beads (Santa Cruz Biotechnology). Equal amounts of protein lysate were electrophoresed on SDS-PAGE gels and transferred to PVDF membrane. Primary antibodies were incubated overnight at $4^{\circ} \mathrm{C}$. Western blotting was visualized by peroxidase-conjugated secondary antibodies and ECL chemiluminescent substrate.

\section{Ulk kinase assay}

Wild-type and mutant Ulk proteins transfected in HEK293T were immunoprecipitated with anti-Myc antibody and protein A/G agarose (Santa Cruz Biotechnology). The immune complex was washed three times with RIPA buffer ( $1 \%$ Triton X-100, 0.5 deoxycholate, $50 \mathrm{mM}$ Tris. $\mathrm{HCl}$ at $\mathrm{pH} 7.5,150 \mathrm{mM} \mathrm{NaCl}, 0.1 \mathrm{mM}$ EDTA, proteinase inhibitors, protein phosphatase inhibitors) and once with kinase assay buffer (20 mM HEPES at $\mathrm{pH} 7.4,1$ mM EGTA, 0.4 mM EDTA, 5 mM $\mathrm{MgCl}_{2}, 0.05 \mathrm{mM}$ DTT) (Kim et al. 2011). Separately transfected HA-Beclin-1 was immunoprecipitated using EZview Red HA-agarose and eluted with HA peptide (Sigma-Aldrich). Kinase reaction was performed by incubating Ulk beads with HA-Belcin-1 elution in kinase assay buffer containing $10 \mu \mathrm{M}$ ATP for $30 \mathrm{~min}$ at $37^{\circ} \mathrm{C}$. Remaining ATP levels in the buffer were determined using a Kinase-Glo kit from Promega. Relative Ulk activity was determined by the amount of ATP consumed.

\section{CaMKII activity assay}

Individually transfected OGT and CaMKII proteins were immunoprecipitated with anti-Myc antibody and protein A/G agarose. The immune complex was washed three times with RIPA buffer and once with assay buffer $(50 \mathrm{mM}$ Tris- $\mathrm{HCl}$ at $\mathrm{pH} 7.5,10 \mathrm{mM}$ $\mathrm{MgCl}_{2}, 0.1 \mathrm{mM}$ EDTA, $2 \mathrm{mM}$ DTT, $0.01 \%$ Brij 35). The OGT and CaMKII beads were mixed and incubated in assay buffer containing $2 \mathrm{mM} \mathrm{CaCl}_{2}, 1.2 \mu \mathrm{M}$ calmodulin (New England BioLabs), and $10 \mu \mathrm{M}$ ATP for $30 \mathrm{~min}$ at $30^{\circ} \mathrm{C}$. Remaining ATP levels in the buffer were determined using a Kinase-Glo kit from Promega. Relative activity was determined by the amount of ATP consumed.

\section{Statistical analyses}

All experiments were repeated at least twice. Results are shown as mean \pm SEM. The comparisons were carried out using twotailed unpaired Student's $t$-test or one-way ANOVA followed by Tukey-adjusted multiple comparisons using Microsoft Excel or GraphPad Prism. No statistical method was used to predetermine sample size. Sample sizes for each group are listed in the figure legends and indicate individual animals (biological replicates). The experiments were not randomized. The investigators were not blinded to group allocation and outcome assessment.

\section{Acknowledgments}

We thank Ira Tabas and Lale Ozcan (Columbia University) for providing liver tissues of Camk2g-LKO and CA-CaMKII mice, E. Olson and J. Backs (University of Texas Southwestern) for providing Camk2 $g^{F / F}$ mice, A.R. Marks (Columbia University) for providing Itpr $1^{F / F}$ mice, A. Iwasaki and G.I. Shulman (Yale University) for providing $\operatorname{Atg} 5^{F / F}$ mice, T. Melia (Yale University) for providing HeLa cells expressing YFP-LC3, X. Yu (University of Michigan) for providing Myc-OGT plasmids, and H. Singer (Albany Medical College) for providing CaMKII plasmids and adenovirus. We thank Michael Jurczak for technical assistance. This work was supported by the National Institutes of Health $\left(\mathrm{NIH}_{\text {; }}\right.$ grants R01DK089098, R01DK102648, and CT DPH2014-0139), the American Cancer Society, and the Ellison Medical Foundation to X.Y.; NIH grant P01DK57751 to A.M.B., B.E.E., M.H.N., 
and X.Y.; and NIH grant P30DK34989 and American Heart Association grant 14SDG20120052 to H.-B.R.

\section{References}

Alers S, Loffler AS, Wesselborg S, Stork B. 2012. Role of AMPKmTOR-Ulk $1 / 2$ in the regulation of autophagy: cross talk, shortcuts, and feedbacks. Mol Cell Biol 32: 2-11.

Alfaro JF, Gong CX, Monroe ME, Aldrich JT, Clauss TR, Purvine SO, Wang Z, Camp DG II, Shabanowitz J, Stanley P, et al. 2012. Tandem mass spectrometry identifies many mouse brain O-GlcNAcylated proteins including EGF domain-specific O-GlcNAc transferase targets. Proc Natl Acad Sci 109: 7280-7285.

Arstila AU, Trump BF. 1968. Studies on cellular autophagocytosis. The formation of autophagic vacuoles in the liver after glucagon administration. Am J Pathol 53: 687-733.

Backs J, Stein P, Backs T, Duncan FE, Grueter CE, McAnally J, Qi X, Schultz RM, Olson EN. 2010. The $\gamma$ isoform of CaM kinase II controls mouse egg activation by regulating cell cycle resumption. Proc Natl Acad Sci 107: 81-86.

Bond MR, Hanover JA. 2013. O-GlcNAc cycling: a link between metabolism and chronic disease. Annu Rev Nutr 33: 205-229.

Bullen JW, Balsbaugh JL, Chanda D, Shabanowitz J, Hunt DF, Neumann D, Hart GW. 2014. Cross-talk between two essential nutrient-sensitive enzymes: O-GlcNAc transferase (OGT) and AMP-activated protein kinase (AMPK). I Biol Chem 289: 10592-10606.

Cheung WD, Hart GW. 2008. AMP-activated protein kinase and p38 MAPK activate O-GlcNAcylation of neuronal proteins during glucose deprivation. J Biol Chem 283: 13009-13020.

Codogno P, Meijer AJ. 2013. Autophagy in the liver. J Hepatol 59: 389-391.

D'Alessio D. 2011. The role of dysregulated glucagon secretion in type 2 diabetes. Diabetes Obesity Metab 13: 126-132.

Decuypere JP, Welkenhuyzen K, Luyten T, Ponsaerts R, Dewaele M, Molgo J, Agostinis P, Missiaen L, De Smedt H, Parys JB, et al. 2011. Ins $(1,4,5) \mathrm{P} 3$ receptor-mediated $\mathrm{Ca} 2+$ signaling and autophagy induction are interrelated. Autophagy 7: 1472-1489.

Deter RL, Baudhuin P, De Duve C. 1967. Participation of lysosomes in cellular autophagy induced in rat liver by glucagon. J Cell Biol 35: C11-C16.

Egan DF, Shackelford DB, Mihaylova MM, Gelino S, Kohnz RA, Mair W, Vasquez DS, Joshi A, Gwinn DM, Taylor R, et al. 2011. Phosphorylation of ULK1 (hATG1) by AMP-activated protein kinase connects energy sensing to mitophagy. Science 331: 456-461.

Erickson JR, Pereira L, Wang L, Han G, Ferguson A, Dao K, Copeland RJ, Despa F, Hart GW, Ripplinger CM, et al. 2013. Diabetic hyperglycaemia activates CaMKII and arrhythmias by $\mathrm{O}-$ linked glycosylation. Nature 502: 372-376.

Ezaki J, Matsumoto N, Takeda-Ezaki M, Komatsu M, Takahashi K, Hiraoka Y, Taka H, Fujimura T, Takehana K, Yoshida M, et al. 2011. Liver autophagy contributes to the maintenance of blood glucose and amino acid levels. Autophagy 7: 727-736.

Feriod CN, Nguyen L, Jurczak MJ, Kruglov EA, Nathanson MH, Shulman GI, Bennett AM, Ehrlich BE. 2014. Inositol 1,4,5-trisphosphate receptor type II (InsP3R-II) is reduced in obese mice, but metabolic homeostasis is preserved in mice lacking InsP3R-II. Am J Physiol Endocrinol Metab 307: E1057-E1064.

Feriod CN, Gustavo Oliveira A, Guerra MT, Nguyen L, Mitchell Richards K, Jurczak MJ, Ruan H-B, Paulo Camporez J, Yang X, Shulman GI, et al. 2017. Hepatic inositol 1,4,5 trisphosphate receptor type 1 mediates fatty liver. Hepatol Commun 1: 23-35.

Goldberg HJ, Whiteside CI, Hart GW, Fantus IG. 2006. Posttranslational, reversible O-glycosylation is stimulated by high glucose and mediates plasminogen activator inhibitor-1 gene expression and Sp1 transcriptional activity in glomerular mesangial cells. Endocrinology 147: 222-231.

Guo B, Liang Q, Li L, Hu Z, Wu F, Zhang P, Ma Y, Zhao B, Kovacs AL, Zhang Z, et al. 2014. O-GlcNAc-modification of SNAP-29 regulates autophagosome maturation. Nat Cell Biol 16: 1215-1226.

Hanover JA, Krause MW, Love DC. 2012. Bittersweet memories: linking metabolism to epigenetics through O-GlcNAcylation. Nat Rev Mol Cell Biol 13: 312-321.

Hara T, Nakamura K, Matsui M, Yamamoto A, Nakahara Y, Suzuki-Migishima R, Yokoyama M, Mishima K, Saito I, Okano H, et al. 2006. Suppression of basal autophagy in neural cells causes neurodegenerative disease in mice. Nature 441: $885-889$.

Hart GW, Slawson C, Ramirez-Correa G, Lagerlof O. 2011. Cross talk between O-GlcNAcylation and phosphorylation: roles in signaling, transcription, and chronic disease. Annu Rev Biochem 80: 825-858.

Huttlin EL, Jedrychowski MP, Elias JE, Goswami T, Rad R, Beausoleil SA, Villen J, Haas W, Sowa ME, Gygi SP. 2010. A tissuespecific atlas of mouse protein phosphorylation and expression. Cell 143: 1174-1189.

Jiang G, Zhang BB. 2003. Glucagon and regulation of glucose metabolism. Am I Physiol Endocrinol Metab 284: E671-E678.

Jozwiak P, Forma E, Brys M, Krzeslak A. 2014. O-GlcNAcylation and metabolic reprograming in cancer. Front Endocrinol 5: 145.

Kang JG, Park SY, Ji S, Jang I, Park S, Kim HS, Kim SM, Yook JI, Park YI, Roth J, et al. 2009. O-GlcNAc protein modification in cancer cells increases in response to glucose deprivation through glycogen degradation. J Biol Chem 284: 34777-34784.

Kim J, Kundu M, Viollet B, Guan KL. 2011. AMPK and mTOR regulate autophagy through direct phosphorylation of Ulk1. Nat Cell Biol 13: 132-141.

Klionsky DI, Abdalla FC, Abeliovich H, Abraham RT, AcevedoArozena A, Adeli K, Agholme L, Agnello M, Agostinis P, Aguirre-Ghiso JA, et al. 2012. Guidelines for the use and interpretation of assays for monitoring autophagy. Autophagy 8: 445-544.

Komatsu M. 2012. Liver autophagy: physiology and pathology. I Biochem 152: 5-15.

Komatsu M, Waguri S, Ueno T, Iwata J, Murata S, Tanida I, Ezaki J, Mizushima N, Ohsumi Y, Uchiyama Y, et al. 2005. Impairment of starvation-induced and constitutive autophagy in Atg7-deficient mice. J Cell Biol 169: 425-434.

Levine B, Kroemer G. 2008. Autophagy in the pathogenesis of disease. Cell 132: 27-42.

Li M-D, Ruan H-B, Hughes ME, Lee J-S, Singh JP, Jones SP, Nitabach MN, Yang X. 2013. O-GlcNAc signaling entrains the circadian clock by inhibiting BMAL1/CLOCK ubiquitination. Cell Metab 17: 303-310.

Lin SY, Li TY, Liu Q, Zhang C, Li X, Chen Y, Zhang SM, Lian G, Liu Q, Ruan K, et al. 2012. GSK3-TIP60-ULK1 signaling pathway links growth factor deprivation to autophagy. Science 336: 477-481.

Medina DL, Di Paola S, Peluso I, Armani A, De Stefani D, Venditti R, Montefusco S, Scotto-Rosato A, Prezioso C, Forrester A, et al. 2015. Lysosomal calcium signalling regulates autophagy through calcineurin and TFEB. Nat Cell Biol 17: 288-299. 
Naito T, Kuma A, Mizushima N. 2013. Differential contribution of insulin and amino acids to the mTORC1-autophagy pathway in the liver and muscle. J Biol Chem 288: 21074-21081.

Nazio F, Strappazzon F, Antonioli M, Bielli P, Cianfanelli V, Bordi M, Gretzmeier C, Dengjel J, Piacentini M, Fimia GM, et al. 2013. mTOR inhibits autophagy by controlling ULK1 ubiquitylation, self-association and function through AMBRA1 and TRAF6. Nat Cell Biol 15: 406-416.

Ozcan L, Wong CC, Li G, Xu T, Pajvani U, Park SK, Wronska A, Chen BX, Marks AR, Fukamizu A, et al. 2012. Calcium signaling through CaMKII regulates hepatic glucose production in fasting and obesity. Cell Metab 15: 739-751.

Park S, Lee Y, Pak JW, Kim H, Choi H, Kim JW, Roth J, Cho JW. 2015. O-GlcNAc modification is essential for the regulation of autophagy in Drosophila melanogaster. Cell Mol Life Sci 72: 3173-3183.

Pfleiderer PJ, Lu KK, Crow MT, Keller RS, Singer HA. 2004. Modulation of vascular smooth muscle cell migration by calcium/ calmodulin-dependent protein kinase II- $\delta_{2}$. Am J Physiol Cell Physiol 286: C1238-C1245.

Rabinowitz JD, White E. 2010. Autophagy and metabolism. Science 330: 1344-1348.

Ruan HB, Han X, Li MD, Singh JP, Qian K, Azarhoush S, Zhao L, Bennett AM, Samuel VT, Wu J, et al. 2012. O-GlcNAc transferase/host cell factor $\mathrm{C} 1$ complex regulates gluconeogenesis by modulating PGC-1a stability. Cell Metab 16: 226-237.

Ruan HB, Nie Y, Yang X. 2013a. Regulation of protein degradation by O-GlcNAcylation: crosstalk with ubiquitination. Mol Cell Proteomics 12: 3489-3497.

Ruan HB, Singh JP, Li MD, Wu J, Yang X. 2013b. Cracking the OGlcNAc code in metabolism. Trends Endocrinol Metab 24: 301-309.

Rubinsztein DC, Codogno P, Levine B. 2012. Autophagy modulation as a potential therapeutic target for diverse diseases. Nat Rev Drug Discov 11: 709-730.

Russell RC, Tian Y, Yuan H, Park HW, Chang YY, Kim J, Kim H, Neufeld TP, Dillin A, Guan KL. 2013. ULK1 induces autophagy by phosphorylating Beclin-1 and activating VPS34 lipid kinase. Nat Cell Biol 15: 741-750.

Schworer CM, Mortimore GE. 1979. Glucagon-induced autophagy and proteolysis in rat liver: mediation by selective deprivation of intracellular amino acids. Proc Natl Acad Sci 76: 3169-3173.

Shafi R, Iyer SP, Ellies LG, O'Donnell N, Marek KW, Chui D, Hart GW, Marth JD. 2000. The O-GlcNAc transferase gene resides on the X chromosome and is essential for embryonic stem cell viability and mouse ontogeny. Proc Natl Acad Sci 97: 57355739.

Shang L, Chen S, Du F, Li S, Zhao L, Wang X. 2011. Nutrient starvation elicits an acute autophagic response mediated by Ulk 1 dephosphorylation and its subsequent dissociation from AMPK. Proc Natl Acad Sci 108: 4788-4793.

Shintani T, Klionsky DJ. 2004. Autophagy in health and disease: a double-edged sword. Science 306: 990-995.
Singh R, Kaushik S, Wang Y, Xiang Y, Novak I, Komatsu M, Tanaka K, Cuervo AM, Czaja MJ. 2009. Autophagy regulates lipid metabolism. Nature 458: 1131-1135.

Sun Z, Miller RA, Patel RT, Chen J, Dhir R, Wang H, Zhang D, Graham MJ, Unterman TG, Shulman GI, et al. 2012. Hepatic $\mathrm{Hdac} 3$ promotes gluconeogenesis by repressing lipid synthesis and sequestration. Nat Med 18: 934-942.

Takamura A, Komatsu M, Hara T, Sakamoto A, Kishi C, Waguri S, Eishi Y, Hino O, Tanaka K, Mizushima N. 2011. Autophagy-deficient mice develop multiple liver tumors. Genes Dev 25: 795-800.

Taylor RP, Parker GJ, Hazel MW, Soesanto Y, Fuller W, Yazzie MJ, McClain DA. 2008. Glucose deprivation stimulates OGlcNAc modification of proteins through up-regulation of O-linked N-acetylglucosaminyltransferase. I Biol Chem 283: 6050-6057.

Torres CR, Hart GW. 1984. Topography and polypeptide distribution of terminal $\mathrm{N}$-acetylglucosamine residues on the surfaces of intact lymphocytes. Evidence for O-linked GlcNAc. I Biol Chem 259: 3308-3317.

Trinidad JC, Barkan DT, Gulledge BF, Thalhammer A, Sali A, Schoepfer R, Burlingame AL. 2012. Global identification and characterization of both O-GlcNAcylation and phosphorylation at the murine synapse. Mol Cell Proteomics 11: 215-229.

Veerababu G, Tang J, Hoffman RT, Daniels MC, Hebert LF Jr, Crook ED, Cooksey RC, McClain DA. 2000. Overexpression of glutamine: fructose-6-phosphate amidotransferase in the liver of transgenic mice results in enhanced glycogen storage, hyperlipidemia, obesity, and impaired glucose tolerance. Diabetes 49: 2070-2078.

Wang P, Lazarus BD, Forsythe ME, Love DC, Krause MW, Hanover JA. 2012. O-GlcNAc cycling mutants modulate proteotoxicity in Caenorhabditis elegans models of human neurodegenerative diseases. Proc Natl Acad Sci 109: 1766917674.

Whelan SA, Dias WB, Thiruneelakantapillai L, Lane MD, Hart GW. 2010. Regulation of insulin receptor substrate 1 (IRS-1)/ AKT kinase-mediated insulin signaling by O-linked $\beta$-N-acetylglucosamine in 3T3-L1 adipocytes. I Biol Chem 285: 5204-5211.

Woods A, Dickerson K, Heath R, Hong SP, Momcilovic M, Johnstone SR, Carlson M, Carling D. 2005. $\mathrm{Ca}^{2+} /$ calmodulin-dependent protein kinase kinase- $\beta$ acts upstream of AMPactivated protein kinase in mammalian cells. Cell Metab 2: 21-33.

Xu Q, Yang C, Du Y, Chen Y, Liu H, Deng M, Zhang H, Zhang L, Liu T, Liu Q, et al. 2014. AMPK regulates histone H2B OGlcNAcylation. Nucleic Acids Res 42: 5594-5604.

Yang X, Qian K. 2017. Protein O-GlcNAcylation: emerging mechanisms and functions. Nat Rev Mol Cell Biol 18: 452465.

Yang X, Ongusaha PP, Miles PD, Havstad JC, Zhang F, So WV, Kudlow JE, Michell RH, Olefsky JM, Field SJ, et al. 2008. Phosphoinositide signalling links O-GlcNAc transferase to insulin resistance. Nature 451: 964-969. 


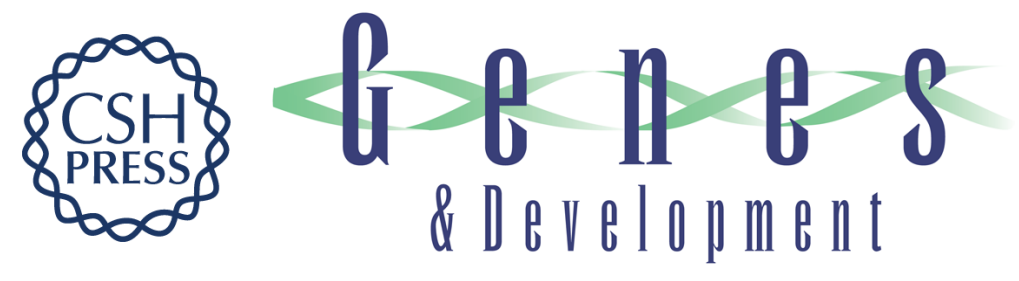

\section{Calcium-dependent O-GIcNAc signaling drives liver autophagy in adaptation to starvation}

Hai-Bin Ruan, Yina Ma, Sara Torres, et al.

Genes Dev. 2017, 31: originally published online September 13, 2017

Access the most recent version at doi:10.1101/gad.305441.117

\section{Supplemental http://genesdev.cshlp.org/content/suppl/2017/09/13/gad.305441.117.DC1 Material}

References This article cites 61 articles, 24 of which can be accessed free at: http://genesdev.cshlp.org/content/31/16/1655.full.html\#ref-list-1

Creative This article is distributed exclusively by Cold Spring Harbor Laboratory Press for the first Commons six months after the full-issue publication date (see

License http://genesdev.cshlp.org/site/misc/terms.xhtml). After six months, it is available under a Creative Commons License (Attribution-NonCommercial 4.0 International), as described at http://creativecommons.org/licenses/by-nc/4.0/.

Email Alerting Receive free email alerts when new articles cite this article - sign up in the box at the top Service right corner of the article or click here.

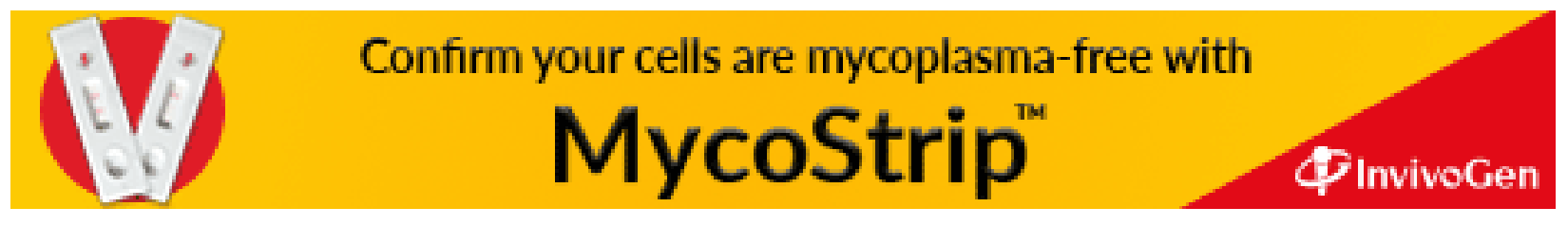

